\title{
Coevolution Takes the Sting Out of It: Evolutionary Biology and Mechanisms of Toxin Resistance in Animals
}

\author{
Kevin Arbuckle ${ }^{1,2, \star}$, Ricardo C. Rodríguez de la Vega ${ }^{3 \dagger}$, and Nicholas R. Casewell ${ }^{4 \ddagger}$ \\ ${ }^{1}$ Department of Biosciences, College of Science, Swansea University, SA2 8PP, \\ United Kingdom; \\ ${ }^{2}$ Department of Evolution, Ecology and Behaviour, Biosciences Building, University of \\ Liverpool, Crown Street, Liverpool, Merseyside L69 7ZB, United Kingdom; \\ ${ }^{3}$ Ecologie Systematique Evolution, UMR8079, CNRS, University of Paris-Sud, \\ AgroParisTech, Université Paris-Saclay, 91400 Orsay, France; \\ ${ }^{4}$ Alistair Reid Venom Research Unit, Parasitology Department, Liverpool School of \\ Tropical Medicine, Pembroke Place, Liverpool, L3 5QA, United Kingdom;
}

Corresponding authors:

* corresponding author (kevin.arbuckle@swansea.ac.uk)

† corresponding author (ricardo.rodriguezdelavega@gmail.com; ricardo.rodriguez-de-

la-vega@u-psud.fr)

‡ corresponding author (nicholas.casewell@Istmed.ac.uk)

\section{Abstract}

Understanding how biotic interactions shape the genomes of the interacting species is a long-sought goal of evolutionary biology that has been hampered by the scarcity of tractable systems in which specific genomic features can be linked to complex phenotypes involved in interspecific interactions. In this review we present the compelling case of evolved resistance to the toxic challenge of venomous or poisonous animals as one such system. Animal venoms and poisons can be comprised of few or of many individual toxins. Here we show that resistance to animal toxins has evolved multiple times across metazoans, although it has been documented more often in phyla that feed on chemically-armed animals than in prey of venomous or poisonous predators. We review three types of gene-product based resistance: 1) toxin scavenging, where molecules produced by the envenomed organism bind and inactivate the toxins; 2) target-site insensitivity, including landmark cases of convergent changes that make the molecules normally targeted by animal toxins refractory, and; 3) off-target repurposing, where envenomed organisms overcome toxicity by exploiting the function of toxins to alter their physiological effect. We finish by discussing the evolutionary processes that likely played a role in the origin and maintenance of toxin resistance. We conclude that antagonistic interactions involving poisonous or venomous animals are unparalleled models for investigating microevolutionary processes involved in coevolution and linking them to macroevolutionary patterns.

\section{Introduction}

Recurrent interactions between species are thought to generate coevolutionary dynamics such that, as one species evolves, selective pressures on the other change (Carval and Ferriere, 2010), eventually leading to genotypic changes due to reciprocal selection, i.e. coadaptation (Clayton et al., 2015). Antagonistic interactions are often 
considered the major driving force of coadaptation, as they are frequent in nature and in many contexts (e.g. predator-prey) are associated with severe fitness consequences. Consequently, antagonistic coevolution has been the focus of a wide range of theoretical models (Van Valen 1973; Dawkins and Krebs, 1979; Vermeij, 1987; Stahl et al., 1999; Thompson, 1999). Antagonistic interactions generate evolutionary battlefields with deployed "arms" that may be anything from behavioural to molecular traits (e.g. fast running speed or venom, respectively). In a simple case where "effector" molecules produced and deployed by one organism target "receptor" molecules in another, and insofar as these molecules have simple genetic bases, this can offer a direct link between identifiable genomic features and complex multi-organism phenotypic outcomes. In this sense, antagonistic interactions involving chemically-armed animals (whether poisonous or venomous) provide an unparalleled model for investigating microevolutionary processes involved in coevolution and linking them to macroevolutionary patterns.

Animal poisons and venoms are two types of toxic secretions distinguished by whether or not the delivery mechanism involves the infliction of a wound by specialized organs or cells (Mebs, 2002; Nelsen et al., 2014). Animal venoms and poisons can be complex mixtures of molecules (Fry et al., 2009; Brodie, 2009), but we argue that only the molecules whose selected function is exerted in the context of an ecologically meaningful antagonistic interaction can rightly be called "toxins". In this review we refer to venoms and poisons as the secreted mixtures of molecules produced by an animal, and to toxins as the individual components of these mixtures selected to exert an extra-organismal function in the context of antagonistic interactions (Fry et al., 2009). While venoms can serve for functions including defence and prey subjugation (Casewell et al., 2013; Calvete, 2017), the biological function of poisons is strictly predator deterrence (Harris and Arbuckle, 2016), which is often associated with other phenotypic cues (Santos et al., 2016). The processes of adaptation in chemically-armed animals and their prey or predators include functional divergence (e.g. paralogous proteins targeting different receptors in both prey and predators [Wong and Belov, 2012]), convergent neofunctionalization (e.g. unrelated proteins with the same derived function after recruitment or duplication [Guenneugues and Menez, 1997]), convergent recruitment (i.e. homologous genes in different lineages being repeatedly recruited for the same, novel, function [Fry et al., 2009; Christin et al., 2010]) and convergent resistance to toxins (e.g. genetic convergence, with the same modifications in toxin receptors of different lineages of predators feeding on toxic prey [Drabeck et al., 2015; Ujvari et al., 2015]).

At the macroevolutionary scale, species and populations that have evolved resistance to their chemically-armed enemies (whether venomous or poisonous) provide opportunities for testing codiversification of both weapons and resistance mechanisms in the context of arms races (Brodie and Brodie, 1999a). Among the few systems studied so far, the best-known include garter snakes resistant to the tetrodotoxin found in their newt prey (e.g. Brodie and Ridenhour, 2003; Feldman et al., 2010; McGlothlin et al., 2014), mongooses resistant to the neurotoxins in their cobra prey (Barchan et al., 1992), and ground squirrels and opossums resistant to rattlesnake venom (Biardi and Coss, 2011; Voss and Jansa, 2012). These studies have shown that the mechanism of resistance is specific to the venom components or toxins to which these animals have been evolutionarily exposed and, thus, is assumed the result of selection imposed by a chemically-armed enemy. To demonstrate the reciprocal event, i.e. that the chemically- 
armed enemy has in turn modified their venom or toxin in response to selection by the anti-chemical defenses of their opponent, has been decidedly more difficult. At best, studies have been able so far to show geographic covariation between toxicity and resistance (e.g. [Rowe and Rowe, 2015; Holding et al., 2016a]), suggesting reciprocal evolutionary responses. However, given the complex composition of most venoms and the difficulty in determining the source or biosynthetic pathway for non-ribosomally synthesized or environmentally acquired toxins (such as bufadienolides produced by toads [Rodríguez et al., 2017] or tetrodotoxin accumulated by various animals [Bane et al. 2014]), it has been difficult so far to investigate reciprocal molecular changes in venom or poison composition and on the production or accumulation of individual toxins that increase toxicity. In this paper we review our current knowledge of evolved resistance to animal venoms and poisons, which we refer to under the umbrella term "toxin resistance", first by describing the diversity of toxin resistance in the animal kingdom, before detailing the mechanisms that give rise to known examples of toxin resistance and finishing by discussing an evolutionary framework that may underpin co-evolutionary interactions between chemically-armed animals and their natural enemies. Whereas multiple analogies could be drawn from the best studied case of disease/pathogen resistance, i.e. the ability of a host to reduce the pathogen load, or tolerance, i.e. the relative host fitness at a given pathogen load (Schneider and Ayres, 2008), we keep the term "toxin resistance" to encompass the evolutionary mechanisms that confer upon an intoxicated animal the ability to resist or tolerate an otherwise deleterious toxic challenge.

\section{Diversity and evolution of toxin resistance}

\subsection{Toxin resistance in the context of this review}

The evolution of toxic weaponry such as poison or venom has occurred multiple times throughout the animal kingdom (Casewell et al., 2013; Harris and Arbuckle, 2016). Since all such weaponry is intimately tied into the concept of 'evolutionary arms races' (Arbuckle, 2017), it is perhaps unsurprising that resistance to it has also evolved on many occasions across the evolutionary history of animals. Nevertheless, the literature on toxin resistance has been reviewed far less often than that of the evolution of the toxins themselves and we aim to address this deficit herein. However, we would also encourage readers to refer to a rare, recent, and noteworthy exception of a review paper that focused on the evolution of resistance, in this case in the context of venomous animals (Holding et al. 2016b). While the relative scarcity of studies focusing on toxin resistance ultimately mean there is a degree of overlap between this review and that of Holding et al. (2016b), particularly relating to the specific mechanisms of resistance outlined in Section 3, our review seeks a broader scope by discussing the evolution of toxin resistance in general (i.e. not solely venomous animals) and by also conceptualising the evolutionary biology underpinning resistant interactions between animals.

For the purposes of this review we use the term 'toxin resistance' broadly to refer to the ability of an animal to avoid or limit the harm that would normally be inflicted when exposed to whole animal venoms or poisons. Although there is a substantial literature on the evolution of resistance to bacterial and human-made toxins used in pest control and disease vectors (e.g. Twigg et al., 2002; Heckel et al., 2007; Tabashnik et al., 2008; Song et al., 2011; Ffrench-Constant, 2013), we restrict our discussion to instances of 
toxin resistance involving ecologically relevant antagonistic interactions between chemically armed animals and their foes. Compared to purely anthropogenic cases, naturally occurring interactions are more likely to relate to general evolutionary patterns than the special cases of targeted eradication programmes where selection pressures for resistance are anticipated to be artificially high. We also recognise that resistance to antibiotics and other antimicrobial drugs could be considered under the broad heading of "toxin resistance" (Martínez, 2008), but as these subjects have been covered by reviews within the medical and microbiological literature (e.g. White et al., 2002; Davies and Davies, 2010) we once more restrict our focus in the current review to toxin resistance in animals.

Just as toxic weaponry in animals has evolved for multiple functions, most commonly predation and defence (Arbuckle, 2017), toxin resistance has evolved as a countermeasure to both of these functions. For instance, where prey have evolved poison as an effective antipredator defence, predators may be selected to evolve resistance to those poisons as a means of exploiting nutritional resources unavailable to many potentially competing predator species. One well-studied example of this is the predatory resistance of garter snakes to the tetrodotoxin-based defence of their California newt prey (e.g. Brodie et al., 2005). An alternative to this predatory toxin resistance, defensive resistance may also occur wherein prey species which are eaten by venomous predators evolve resistance to increase their chances of escaping once attacked (McCabe and Mackessy, 2017). For example, Californian ground squirrels have been shown to be relatively resistant to several venom components of their northern Pacific rattlesnake predators, particularly snake venom metalloproteinases and haemolytic toxins (Biardi et al. 2006). Besides the handful of examples of evolved defensive resistance of snake prey further discussed below, there is little evidence for prey of the vast majority of venomous predator clades (McCabe and Mackessy, 2017), whereas predatory resistance to toxins from prey is more commonly found.

We should note that, although presented as alternatives, predatory and defensive venom resistance are not necessarily mutually exclusive even when resistance to the same toxins is involved. Recent work on the resistance of South American opossums to haemorrhagic venom components of sympatric pitvipers has typically been interpreted as an adaptation to facilitate predation on their (potentially) dangerously venomous prey (Jansa and Voss, 2011). A similar scenario has been suggested for many other snake venom resistant mammals as many of these also prey on venomous snakes (Voss and Jansa, 2012). However, Voss (2013) highlighted that the same venom resistant opossum species that are known to prey on pitvipers are also eaten by these snakes. Hence, the coevolutionary arms race set up in this case can lead to venom resistance being used both for predation and defence by opossums, a scenario that can be effective contemporaneously and over evolutionary time as venom and venom resistance coevolve. Such 'role-switching' confers dual benefits to venom resistance, but so far good examples of it are rare; this may either reflect a true rarity of the strategy or simply a lack of directed investigation and is therefore likely to be a fruitful area for further research.

\subsection{Toxin resistance is widespread across the animal tree of life}


One of the most striking aspects of toxin resistance is the wide range of animals in which it has evolved. Documented examples of the phenomenon are found scattered across the animal tree of life (Fig. 1). Note that toxin resistance appears especially frequent amongst tetrapods, although with current knowledge it is difficult to assert whether this is the result of resistance being more common in this group or whether it is simply due to sampling biases due to higher research effort on tetrapods. The taxonomic diversity encompassed by animals with described toxin resistance includes many examples of resistance to both venoms and poisons, and for both predatory and defensive functions. Taking mammals as an example, we find predators such as hedgehogs and grasshopper mice with resistance to the venom of their viper and scorpion prey respectively (de Wit and Weström, 1987; Rowe and Rowe, 2008), and we also find numerous North American rodent species that are resistant to the venom of their pitviper predators (Perez et al., 1979; de Wit, 1982; Poran et al., 1987). With regard to poison, which can only be used for defence rather than predation (Nelsen et al., 2014; Harris and Arbuckle, 2016), toxin resistance has allowed many species access to foodstuffs that are presumable unavailable to other consumers, such as poisonous toads that are eaten by several toxin resistant predators (Ujvari et al., 2015).

Autoresistance (see section 3.4 below) is a common function of toxin resistance (Santos et al., 2016), and can be defined as the ability to avoid self-intoxication from toxins used in the same organism's defence or predatory strategy. Note that autoresistance can be considered a distinct function from predation or defence as the resistance has not evolved in response to the toxins of another organism, but rather to its own toxins (even though they themselves may serve predatory or defensive roles). Nevertheless, given that a number of toxic animal species are known to feed cannibalistically at least part of the time (Burchfield, 1977; Polis and Myers, 1985; Pizzatto and Shine, 2008), autoresistance can also be linked to predation or defence directly in some cases. Indeed, in species where cannibalism is common it is plausible that the maintenance of autoresistance could be partly driven by such interactions, as suggested for the insensitivity of tarantula ion-channels towards tarantula toxins (Deng et al., 2016).

One potential complication of reports of toxin resistance is that simple observations of animals recovering (or showing no symptoms) from an envenomation or intoxication are difficult to evaluate. Venoms may be energetically costly to produce (McCue, 2006; Nisani et al., 2007; but see Pintor et al. 2010; Smith et al., 2014) and as a result many venomous animals are able to vary the amount injected in a given envenomation (Hayes, 1995; Inceoglu et al., 2003; Nisani and Hayes, 2011; Morgenstern and King, 2013; van der Meijden et al., 2015; Cooper et al., 2017). Furthermore, not all attempts to deliver an envenomation are successful; a snake may achieve only a glancing bite (e.g. Herbert and Hayes, 2009) or a scorpion may only succeed in stinging the thick fur of an assailant. Therefore, depending on the context of the envenomation, the afflicted animal may have only received a small and insubstantial dose rather than be endowed with any degree of toxin resistance. Nevertheless, it seems that, despite an already broad taxonomic and phylogenetic distribution of toxin resistance (Fig. 1), the phenomenon is likely to be even more diverse than we currently know.

\subsection{Toxin resistance commonly evolves by convergent evolution}


Evolutionary convergence can be considered to occur at several levels (Losos, 2011; Speed and Arbuckle, 2017), perhaps the broadest of which in the current context is to treat toxin resistance as the trait regardless of mechanisms, which toxin(s) are involved, or other such distinctions. While this a very heterogeneous definition, it does allow us to recognise that evolutionary pressures favouring mechanisms to avoid intoxication have originated many times across the animal tree of life (Fig. 1). This is all the more striking when we note that each of the red branches in Fig. 1 is either known or strongly suspected to encompass many independent origins of toxin resistance, even without accounting for the underreporting highlighted above.

On a more specific level, documented cases of convergent evolution of resistance to a few particular types of toxins have provided some important insights about evolutionary constraints and the repeatability of evolution. For instance, resistance to alphaneurotoxins from elapid snake venoms has evolved at least four times in mammals (in honey badgers, mongooses, hedgehogs, and pigs) as a consequence of changes to the nicotinic acetylcholine receptor molecule to which those toxins bind (Drabeck et al., 2015). Despite this example of resistance to venom toxins, the better-known cases of convergence in toxin resistance amongst animals relate to poisons, particularly tetrodotoxin and cardiac glycosides (McGlothlin et al. 2014, 2016; Dobler et al. 2012; Ujvari et al. 2015). This is perhaps because venoms are typically far more complex mixtures of toxins than poisons, which may consist of only one or a few components, thereby making the latter a more tractable system for ecologically-relevant analysis. Note that although there has been some debate about the terminology of convergent evolution (some would consider aspects of the following examples to be 'parallel evolution' instead, e.g. resistance to different sodium channel blocker toxins in poisonous pufferfish and clams [Bricelj et al., 2005; Venkatesh et al., 2005; Stern, 2013]), we use convergence as a term that includes parallel evolution. This is in keeping with the lack of clear distinctions between the two concepts (Arendt and Reznick, 2008) and the idea that explicit consideration of convergence at different 'levels of life' encompasses parallelism as a logical extension (Losos, 2011; Speed and Arbuckle, 2017).

\section{Mechanisms of toxin resistance}

\subsection{Resistance via toxin "scavenging"}

The described mechanisms underpinning resistance to animal venoms and poisons can be broadly classified into three groups: (i) "scavenging" molecules, (ii) target-site insensitivity and (iii) "off-target repurposing". Much of the historical work undertaken on toxin resistance inherently relates to exploring inhibition via serum-based components, predominately in venomous snake-resistant mammals (e.g. Perez et al., 1978a; Perez et al., 1978b; Perez et al., 1979; Poran et al., 1987; de Wit and Weström, 1987), where "scavenging" molecules inactivate circulating toxins. Perhaps the most well-known of these systems is the resistance of ground squirrels (Otospermophilus) to North American rattlesnake (Crotalus) venoms. In some regions of North America ground squirrels represent a major proportion of the diet of rattlesnakes in certain habitats (Fitch, 1948). In addition to employing relatively effective avoidance behaviours (Poran and Coss, 1990), some populations of California ground squirrels (Otospermophilus beecheyi) exhibit venom resistance, as first noted by their tolerance to envenomings by 
rattlesnakes (Coss and Owings, 1985). Poran et al. (1987) demonstrated that such resistance covaries as a function of rattlesnake density, with ground squirrels from an area dense with northern Pacific rattlesnakes (Crotalus oreganus) exhibiting significantly higher levels of resistance than those from rattlesnake-free areas. Resistance appears to have been driven by protective factors present in ground squirrel sera, with higher venom binding levels and protection observed when analysing sera from squirrels found sympatrically with rattlesnakes (Poran et al., 1987).

Subsequent work has demonstrated that ground squirrels have serum factors that are capable of neutralising the haemolytic, proteolytic and/or fibrinolytic activities of the toxins known as snake venom metalloproteinases (SVMPs) present in rattlesnake venoms, although this appears highly variable and depends upon whether sympatric or allopatric relationships exist (Biardi et al., 2000; Biardi et al., 2006; Biardi and Coss, 2011; Holding et al. 2016a). Using anion exchange and affinity chromatography, Biardi et al. (2011) showed that $O$. beecheyi that co-exist with rattlesnakes possess circulating SVMP inhibitors that are at least partially responsible for providing this toxin resistance. One of these inhibitors appears to be a member of the immunoglobulin supergene family and shows similarity with inter- $\alpha$ trypsin inhibitor (Biardi et al., 2011), a factor previously known to interact with and modulate matrix metalloproteinases, to which the SVMPs are distantly related (Huxley-Jones et al., 2007; Casewell, 2012). Reports of other types of North American squirrels exhibiting degrees of resistance against rattlesnake venoms via serum based resistance (Perez et al., 1978b; Pomento et al., 2016), provides an interesting model to investigate whether similar inhibitory components have evolved or been convergently upregulated in this mammalian family (Sciuridae).

Interestingly, a number of other mammals possess serum-based enzyme inhibitors that offer varying degrees of protection from the toxins found in viperid snake venoms (see Pérez and Sánchez 1999 and Perales et al., 2005 for comprehensive reviews). While some are found in prey species (e.g. the hispid cotton rat Sigmodon hispidus [Pichyangkul and Perez, 1981] and the Southern Plains woodrat Neotoma micropus [Garcia and Perez, 1984]), the majority that have been characterised to date are present in mammals that are successful snake predators. Notably, many of these serum proteins are also members of the immunoglobulin superfamily, and exhibit similarities to a1 Bglycoprotein and therefore may be present in these varied taxa as a result of convergence. Examples include AHF-1 from the mongoose (Herpestes edwardsii) and DM40, DM43, DM43b, oprin and PO41 from the opossums Didelphis virginiana, D. marsupialis and Philander opossum (Perales et al., 2005). Many of these serum proteins inhibit haemorrhagic SVMPs, as described above for the ground squirrels. For example, DM43 and DM40 were isolated from a fraction of $D$. marsupialis serum that inhibited the lethal, haemorrhagic and proteolytic effects of venom from lancehead snakes (Bothrops) (Neves-Ferreira et al., 2000; Perales Moussatche et al., 1994). It was proposed that DM43 inhibits SVMPs, such as jararhagin, by forming a 1:1 inhibitory complex via a metalloproteinase-binding site formed by six surface exposed loops, thereby preventing toxin function (Fig. 2A) (Neves-Ferreira et al., 2002). Similarly, PO41 from P. opossum was demonstrated to form a 1:1 complex with SVMPs isolated from the viper Bothrops jararaca, resulting in the neutralisation of their proteolytic and haemorrhagic effects (Jurgilas et al., 2003). 
However, as alluded to earlier, many venoms (including those of snakes) are complex protein mixtures, and viper venoms contain other toxin types in addition to SVMPs. Soares et al. (1997) showed that a fraction of serum from the opossum $D$. albiventris neutralised not only the haemorrhagic effects of multiple Bothrops venoms, but also the necrotic, myotoxic, oedematogenic and coagulopathic effects, and induced a reduction in phospholipase $A_{2}$ activity. Subsequently, Rocha et al. (2002) demonstrated that the serum protein DM64 from $D$. marsupialis inhibits the myotoxic activity of phospholipase $\mathrm{A}_{2}$ toxins from $B$. asper venom. Interestingly, DM64 was shown to exhibit high sequence similarity $(\sim 78 \%)$ with DM43 (also from $D$. marsupialis) and oprin (from D. virginiana) (Rocha et al., 2002), demonstrating that similar a1 B-glycoprotein-like serum proteins are capable of neutralising the toxic effects of distinct snake venom components.

Moreover, many studies have shown that several venomous snakes themselves possess inhibitory molecules in their own serum (see additional discussion in section 3.4). These proteins are distinct from those characterised from mammals, and include those demonstrated to inhibit the haemorrhagic, myotoxic and neurotoxic activity of venom metalloproteinases, phospholipases and neurotoxins secreted in their own venom (e.g. Omori-Satoh et al., 1972; Shao et al., 1993; Wang et al., 1995; Lizano et al., 1997, 2000; Ohkura et al., 1997; Faure, 2000; Perales et al., 2005). It therefore appears likely that these components are present to promote autoresistance (i.e. prevent self-toxicity), as many snakes have been reported to exhibit degrees of resistance against their own venom (e.g. Omori-Satoh et al., 1972; Straight et al., 1976; Ovadia and Kochva, 1977; Philpot et al., 1978) and some inhibitory components have been postulated to have coevolved with their toxic counterparts (Wang et al., 1995). However, the diversity or conservation of these different inhibitory molecules and the extent of their taxonomic distribution across venomous snakes remains to be elucidated. It is possible that the production of serum proteins that protect against self-toxicity may also provide some resistance against the venom of closely related snake species in the event of predatory interactions, as there are a number of reports describing toxin inhibition by snake sera and/or specific serum proteins that show cross-species effectiveness (Straight et al., 1976; Ovadia and Kochva, 1977; Tomihara et al., 1990; Omori-Satoh et al., 1994; Thwin and Gopalakrishnakone, 1998).

\subsection{Resistance via target-site insensitivity}

The multi-component nature of snake venoms (and seemingly predatory venoms in general [Fry et al. 2009; Casewell et al., 2013]), makes it perhaps unsurprising that multiple serum-based enzyme inhibitors are found in resistant taxa. However, many venom components are non-enzymatic, and consequently a number of the ophiophagus mammals discussed earlier (mongooses, opossums, etc.) have also evolved molecularbased resistance to snake venom toxins that complement their suite of blood serum inhibitors. The basis for such resistance is the modification of the gene sequences that encode the receptors or circulating proteins which the toxins target (i.e. alteration of "receptor" molecules). Molecular targets can be rendered desensitised or refractory to the toxins via modifications that reduce their binding interactions through conformational changes. A fascinating example of this was observed in the opossums (e.g. Didelphis and Philander) where von Willibrand Factor (vWF), a key component of the haemostatic system, exhibits evidence of adaptive molecular evolution in resistant taxa (Jansa and 
Voss, 2011). Critically, some of the molecular changes observed within the A1 domain of VWF were found to be evolving under the influence of positive selection, and several of these sites corresponded to those found to be important for the binding interactions observed between vWF and the snake venom C-type lectin botrocetin (Fukuda et al., 2005; Jansa and Voss, 2011) - a toxin that induces thrombocytopenia via platelet aggregation by enhancing the affinity of vWF for platelet glycoproteins (Sanders et al., 1988; Read et al., 1989; Fukuda et al., 2005). These molecular changes are predicted to cause substantial alterations to the hydrophobicity and charge of vWF and, consequently, alter the binding interactions with botrocetin (whether directly via ionic interactions or indirectly via steric interactions), but without altering the key residues involved in binding vWF to its normal physiological platelet glycoprotein targets (Jansa and Voss, 2011).

A similar scenario is found in the $\alpha$-subunit of the muscle-type nicotinic acetylcholine receptor ( $\mathrm{nAChR}$ ) in various mammals, where relatively few molecular changes to the ligand binding site dramatically decrease its sensitivity to the a-neurotoxins found in the venom of many elapid snakes. To date, these changes have predominately been identified in mammals that are likely predators of snakes, such as the mongoose (Herpestes ichneumon), honey badger (Mellivora capensis), hedgehogs (Erinaceus concolor and Erinaceus europaeus) and pig (Sus scrofa). These molecular alterations prevent venom neurotoxins from inhibiting synaptic transmission at neuromuscular junctions, and thereby offer protection against the lethal effects of certain snake venoms (Takacs et al., 2001; Drabeck et al., 2015). Interestingly, nAChR amino acid replacements conferring resistance in the honey badger, hedgehogs and pig have evolved via adaptive molecular convergence (Fig. 3A). Drabeck et al. (2015) demonstrated that two sites of the $\mathrm{nAChR}$ ligand binding domain have been altered in all these taxa from ancestral aromatic residues to arginine and leucine or isoleucine (positions 187 and 189, respectively, in the alpha subunit of human nAChR; UniProt: P02708). Replacements at these sites result in reduced affinities for snake venom $\alpha$ neurotoxins (Neumann et al., 1986; Tzartos and Remoundos, 1990; Barchan et al., 1992; Takacs et al., 2001; Dimitropoulos et al., 2011) and, in particular, change at position 187 is thought to be key to the abolition of neurotoxicity through charge interference (Dellisanti et al., 2007a, 2007b; Takacs et al., 2004). Similarly, the mongoose $(H$. ichneumon) has a modified amino acid at position 187 of the nAChR that confers resistance. In this case, however, the replacement results in an asparagine residue, and it is the glycosylation of this amino acid that is responsible for abolishing the binding of $\alpha$-neurotoxins to the receptor via steric hindrance (Dellisanti et al. 2007a, 2007b; Takacs et al., 2001; Takacs et al., 2004). Interestingly, the addition of a glycosylated ( $\mathrm{N}$ glycosylation) asparagine residue, found two amino acid positions adjacent to that observed in the mongoose nAChR ligand binding site (homologous to position 189 in the human $\mathrm{nAChR}$ ), is responsible for providing autoresistance in elapid snakes. Deglycosylation of this residue was demonstrated to render the receptor sensitive to venom neurotoxins (Takacs et al., 2001; Takacs et al., 2004). Thus, $\mathrm{N}$-glycosylation or amino acid replacements in a three amino acid long stretch of the nAChR ligand-binding domain have resulted in the convergent evolution of molecular resistance to snake venom a-neurotoxins in both elapid snakes and several distinct lineages of mammals (Takacs et al., 2001; Takacs et al., 2004; Drabeck et al., 2015). 
Perhaps the best examples of molecular-based resistance to toxins are found when looking at poisonous, rather than venomous, animals. Tetrodotoxin is a potent neurotoxin that also interferes with nerve transmission by binding to voltage-gated sodium $\left(\mathrm{Na}_{\mathrm{v}}\right)$ channels found in nerve and muscle tissue (Soong and Venkatesh, 2006). Tetrodotoxin was first isolated from pufferfish but similar molecules have since been found in the chemical defences of a range of animals including other fishes, amphibians, molluscs and echinoderms (Edstrom, 1992) and in the defensive and predatory venoms of molluscs and arrow worms (Sheumack et al., 1978; Thuesen et al., 1988). Although the origin of the tetrodotoxin present in poisonous and venomous animals has not been elucidated (whereas symbiotic bacteria might be responsible in venomous blue-ringed octopuses, poisonous pufferfishes seems to acquire it from their diet [Bane et al., 2014]) it is reasonable to postulate that these animals may themselves have evolved resistance to tetrodotoxin in order to safely store it for their own toxic purposes (see section 3.4 below). However, a number of animals have evolved resistance to tetrodotoxin, allowing them to prey on those species that harbour the toxin. This includes several snakes which have convergently evolved the ability to feed on tetrodotoxin-containing newts (McGlothlin et al., 2016); in the case of garter snakes this system is so well-known that it has become a standard example of arms race coevolution (see for example the entry in Wikipedia, https://en.wikipedia.org/wiki/Evolutionary_arms_race). Similar to the cases described above, toxin resistance is underpinned by molecular changes to the toxin targets $-\mathrm{Na}_{v}$ channels. In this scenario Geffeney et al. (2005) demonstrated that multiple amino acid substitutions in the pore regions of $\mathrm{Na}_{v}$ channels likely confer resistance to tetrodotoxin in the garter snake Thamnophis sirtalis by altering voltage sensitivity. Interestingly, a number of these changes have evolved convergently in homologous $\mathrm{Na}_{v}$ channel encoding genes; two identical amino acid changes involved in resistance were found in the skeletal muscle channel $\mathrm{Na}_{v} 1.4$ orthologs (Feldman et al., 2012) and also in the peripheral nerve paralogous channels $\mathrm{Na}_{v} 1.6$ and $\mathrm{Na}_{v} 1.7$ (McGlothlin et al., 2014). Fascinatingly, it was recently shown that some of these mutations conferring tetrodotoxin resistance evolved early in reptile evolution prior to the origin of all snakes (and newts possessing tetrodotoxin [Hanifin and Gilly, 2015]), with additional, differential, mutations to various $\mathrm{Na}_{v}$ channels evolving in disparate snake lineages latterly, underlying extreme resistance to tetrodotoxin-harbouring prey (McGlothlin et al., 2016). Because of the fundamental physiological role of the targets of tetrodotoxin in nerve transmission, the viable pathways to resistance are seemingly heavily constrained in terms of what changes to the proteins remain consistent with their function (Feldman et al., 2012; Brodie and Brodie, 2015), resulting in a classic example of convergent molecular evolution. However, other snakes have since been demonstrated to have evolved resistance to tetrodotoxin via completely different, $\mathrm{Na}_{v}$ channel-independent, mechanisms (Feldman et al., 2016), indicating that multiple pathways to resistance exist for this model.

Our final example of this mode of resistance is that of cardiac glycosides. These toxins interfere with cell physiology by binding to the sodium-potassium ion pump $\left(\mathrm{Na}^{+} / \mathrm{K}^{+}-\right.$ ATPase) in cell membranes and perturbing membrane potentials, resulting in cardiotoxicity (Schoner, 2002). They are used in defensive poisons by both plants (e.g. cardenolides in species such as milkweeds and foxgloves) and animals (e.g. bufotoxins in certain amphibians). Dobler et al. (2012) and Zhen et al. (2012) demonstrated that a wide spectrum of insects which feed on cardenolide-containing plants have evolved very 
similar amino acid changes in the $\mathrm{Na}^{+} / \mathrm{K}^{+}$-ATPase molecules which in turn confer resistance to those toxins. Even more surprisingly, Ujvari et al. (2015) found that similar changes to the same region of the $\mathrm{Na}^{+} / \mathrm{K}^{+}$-ATPase have evolved convergently in various reptiles, amphibians and mammals to confer resistance to the cardiac glycosides produced by their bufonid toad prey. Specifically, all resistant taxa were found to have two amino acid changes in a 12 amino acid stretch of the $\mathrm{H} 1-\mathrm{H} 2$ extracellular domain of the various subunits of this protein (Fig. 3B). These changes confer resistance by changing the charge of the molecule and in turn perturb the hydrogen bonding interactions between cardiac glycosides and the $\mathrm{Na}^{+} / \mathrm{K}^{+}$-ATPase, resulting in decreased binding affinities (Ujvari et al., 2015). Considering these similar changes have evolved in parallel in various insects, multiple groups of snakes, varanid lizards, rodents, hedgehogs and certain frogs, this model seemingly represents another example of the evolution of resistant phenotypes via convergent pathways. In an analogous manner to the example of tetrodotoxin discussed above, the existence of sudden reversals of resistance-conferring changes in species which switched away from feeding on toxic prey further argues that functional constraints that lead to physiological costs, and few ways to achieve resistance, are important drivers of convergence (Ujvari et al. 2015). However, the same $\mathrm{Na}^{+} / \mathrm{K}^{+}$-ATPase mutations conferring resistance to cardiac glycosides have been documented in a number of snakes not known to feed on poisonous toads, thus suggesting that either there are minimal physiological costs of the mutations or that they confer some other, as yet unknown, advantage (Mohammadi et al., 2016).

\subsection{Resistance via "off-target repurposing"}

A third mechanism underlying toxin resistance is that off "off-target repurposing". Here molecular changes to the targets of toxins also occurs (in a manner analogous to those examples described above in section 3.2), but in contrast to generating target site insensitivity, off-target repurposing enhances binding affinities such that the physiological effect induced by the toxin is altered. The sole example of this mechanism is the resistance exhibited by grasshopper mice (Onychomys) to the intensely painful and potentially lethal stings of bark scorpions (Centruroides) (Rowe and Rowe, 2008; Rowe et al., 2013). Toxins in the venom of bark scorpions hyperactivate vertebrate sodium and block potassium channels found in nerve and muscle tissues and cause intense pain and neurotoxicity (Rowe et al., 2011). However, despite this toxicity, various species of grasshopper mice readily consume these scorpions in a similar manner to non-lethal scorpions or chemically-defenceless arthropods such as crickets, potentially indicative of venom resistance (Rowe and Rowe, 2006). Laboratory lethality studies demonstrated that many species of grasshopper mice are indeed resistant to bark scorpion venoms, and that the degree of resistance observed corresponds to the degree of sympatry between the mice and scorpions (Rowe and Rowe, 2008). The basis of venom resistance was subsequently investigated by exploring the action of scorpion venom on pain channel receptors and their molecular evolution in grasshopper mice. Scorpion toxins cause pain by activating $\mathrm{Na}_{v}$ channels, particularly $\mathrm{Na}_{v} 1.7$ (Wood, 2013), although others might also be involved (Israel et al., 2017). However, in Onychomys, replacement amino acids in the extracellular loops and pore regions of $\mathrm{Na}_{v} 1.8$ were demonstrated to enhance the binding of scorpion toxins to this previously unaffected channel such that sodium currents and pain signals were actually inhibited, resulting in analgesia (Rowe et 
al. 2013). This remarkable solution for preventing pain caused by venom toxins is underpinned by a single, crucial, acidic amino acid replacement in the domain II SS2-S6 loop of $\mathrm{Na}_{v} 1.8$, and further enhanced by a reciprocal hydrophilic replacement three amino acids upstream of this position (Fig. 2B) (Rowe et al., 2013). Therefore, in contrast to perturbing the interaction between toxin and receptor such that binding is reduced/abolished, in the case of off-target repurposing, resistance is facilitated by enhancing those interactions such that the physiological consequences of toxin binding are altered to the benefit of the targeted animal.

\subsection{Autoresistance}

As described above, there are many examples of toxin-producing animals exhibiting autoresistance against the toxins that they produce, such as the venomous snakes that produce inhibitory molecules in their blood serum (e.g. Thwin and Gopalakrishnakone, 1998; Perales et al. 2005) and exhibit receptor alterations that decrease the sensitivity of their toxins to their own internal physiological target molecules (Takacs et al., 2001; Takacs et al., 2004). Other documented examples of autoresistance, include those from pufferfish (Venkatesh et al., 2005; Jost et al., 2008), toads (Moore et al., 2009; Ujvari et al., 2015), poison frogs (Daly et al., 1980; Tarvin et al., 2016), newts (Brodie and Brodie, 1991; Hanifin and Gilly, 2015), caecilians (Schwartz et al., 1998), millipedes (Duffey and Towers, 1978) and sea anenomes (Meinardi et al., 1995). In combination, this represents an impressive taxonomic and phylogenetic spread, covering most major vertebrate groups and also some invertebrates, but it is almost certainly an underestimate. As highlighted by Santos et al. (2016) in the context of chemical defence, autoresistance is relatively rarely investigated or even explicitly documented from animals, even in cases where it likely exists.

In contrast to the "direct" inhibitors outlined above, autoresistance may also be underpinned by "indirect" processes. For example, venoms may be synthesised and stored in specialised tissues, separate from sites of toxic activities, or stored in an 'inactivated' form and converted to active toxins shortly before envenomation (Mackessy and Baxter, 2006). However, some venom toxins clearly pose sufficient risk to drive the evolution of autoresistance, as do some other types of defences such as the toxins released by holothurians (Edstrom, 1992), which expose the secreting animal to the toxin as much as the target organism and so may also increase risk to the toxin user. Such species must surely be resistant to their own toxins, yet explicit documentation of this is lacking. As a result, with better reporting and a stronger focus on toxin resistance by investigators it is likely that many of the 'gaps' (blue terminal branches) in Fig. 1 will be filled.

Of particular interest is the role that sequestration, wherein animals exploit toxins obtained from their diet for defensive (and rarely predatory) purposes, may play in the evolution of autoresistance. Toxin sequestration is a widespread phenomenon across the animal kingdom (Gleibs and Mebs, 1999; Opitz and Müller, 2009; Savitzky et al., 2012; Harris and Arbuckle, 2016). Species that sequester toxins have provided many interesting examples of toxic animals, including some classical model systems such as dendrobatid frogs that sequester a range of alkaloids from their prey (Santos et al., 2016; Tarvin et al. 2017; Wang and Wang, 2017) and monarch butterflies that sequester 
cardiac glycosides from milkweed plants (Malcolm and Brower, 1989). Furthermore, the best-known species of poisonous birds, such as the pitohuis, use a very similar strategy to dendrobatid frogs to sequester similar toxins (Dumbacher et al., 2004). In some of these examples, and a few others, the natural history of toxin sequestration has been studied to a level that gives us a reasonable understanding of how sequestration functions in the ecology of the species. For instance, Asian tiger snakes (Rhabdophis tigrinus) sequester bufodienolides, a group of cardiac glycosides, from their toad prey and store these in specialised nuchal glands which are directed towards a predator during an encounter (Hutchinson et al., 2007). The toxins ingested in the diet undergo several modifications including hydrolytic cleavage of side chains, hydroxylation reactions in the steroid ring system, and epimerisation, which are likely involved in the transport and storage of the toxins during sequestration (Hutchinson et al., 2012). Populations of $R$. tigrinus that do not have toad prey available are not poisonous (though they are still venomous), indicating that toads are vital to the procurement of defensive nuchal gland toxins (Hutchinson et al., 2012). Moreover, this species also exhibits maternal provisioning of nuchal gland toxins to their offspring as mothers deposit bufodienolides on their eggs (Hutchinson et al., 2008). Gravid females are known to shift their foraging behaviour to actively search for (scarce) toads, a potentially adaptive behaviour arguably selected because it provides higher levels of bufodienolides to the offspring, thus enhancing their chemical defence and potential survival (Kojima and Mori, 2015).

More generally, however, the physiological mechanisms that enable toxin sequestration from dietary items are poorly known (Santos et al., 2016). It is difficult to envisage any such mechanism that does not involve resistance to poison or venom in the diet and consequently autoresistance to the sequestered toxins. However, apart from a few, relatively scarce, examples such as those discussed above, there is little published consideration of autoresistance as a component of the toxin acquisition strategy employed by animals that sequester toxins. Interestingly, Petschenka and Agrawal (2015) found that in the caterpillars of Danaini butterflies, which sequester cardiac glycosides from their milkweed diet, mutations in the $\mathrm{Na}^{+} / \mathrm{K}^{+}$-ATPase which confer resistance are not necessary to feeding on the amount of toxins present in the plants. However, these mutations are essential to enable sequestration of the high levels of these toxins required for their own defence. This suggests that the evolution of autoresistance in this species has been driven by the need to sequester toxins rather than by feeding on toxic plants per se. The generality of this to other animals showing autoresistance remains unknown, but given that the primary paradigm is the evolution of resistance to permit feeding on a toxin-rich diet, which then allows sequestration for defence, it is an interesting alternative evolutionary pathway that would be fruitful to explore further.

\section{Evolutionary biology of toxin resistance}

\subsection{Origin of resistance}

Although our understanding of the molecular basis of toxin resistance is still incomplete, some general patterns have emerged from a relatively wide range of systems. In 
contrast, the general patterns in the evolutionary origin of toxin resistance have received less attention in the literature, although a few studies have provided some interesting perspectives. In particular, Gould and Vrba's (1982) concept of exaptation seems to underlie multiple cases of resistance in that molecular changes which evolved under an unrelated regime of selection subsequently confer resistance to a particular toxin. The generality of this idea remains to be fully explored, but given that the initial ability to consume toxic prey (at least to some degree) would provide the stage for coevolution to subsequently take place, it may well prove to be a common pathway. Note that even if the toxin(s) only arises after the exapted 'toxin resistance' mechanism, it clearly will then be under additional selection pressure to be maintained for the purposes of resistance.

One example of exaptation as a route to toxin resistance is provided by a-neurotoxins from snake venoms. These toxins are particularly common in elapid snakes, in which they are often among the main contributors to prey subjugation and death, and bind to nicotinic acetylcholine receptors which leads to failure of signal transmission across the neuromuscular junction. Takacs et al. (2004) postulated that, in cobras, auto-resistance to $\alpha$-neurotoxins evolved first by a mechanism which exapted the snakes to be resistant to different $\alpha$-neurotoxins found in other venomous snake species. Cobra long-chain $\alpha-$ neurotoxins are the target toxins driving selection for mutations conferring autoresistance but, despite being structurally and functionally distinct, resistance to short-chain $\alpha$ neurotoxins of other elapid species is also conferred incidentally by those same mutations. However, on an even broader scale than this, Burden et al. (1975) demonstrated that resistance to snake venom $\alpha$-neurotoxins is actually found across a wide range of snakes and closely-related lizard groups. This suggests that the resistance to these toxins may have evolved long before the toxins themselves originated in a particular group of snakes, once again arguing for an exaptation-driven origin of toxin resistance.

A further example is provided by McGlothlin et al.'s (2016) work on tetrodotoxin resistance, as discussed earlier in the context of molecular mechanisms involved in resistance. Notably, tetrodotoxin resistance in reptiles was not a case of evolution of a fully resistant phenotype before the origin of the toxin in prey species, but rather the early origination of mutations conferring some degree of resistance followed by a stepwise series of additional mutations which led to a higher degree of resistance. Nevertheless, despite further evolutionary events contributing to the current phenotype in species which regularly eat tetrodotoxin-defended prey, this was facilitated by exaptations which allowed coevolutionary processes to begin.

\subsection{Should animals evolve resistance to one, few, or many toxins?}

Chemically-armed organisms may employ a single toxin, a complex mixture of important toxins, or something in between, such as one or few toxins responsible for a major part of the lethal effect and many other minor toxic or non-toxic (but facilitative) components, or components selected under different antagonistic interactions (e.g. predatory and defensive venoms in Conus snails [Dutertre et al., 2014]). In the case of a single toxin, resistance is necessarily straightforward in the sense that only one chemical has to be counteracted. However, where multiple toxins are used in the chemical arsenal of predator or prey there are options as to which (and how many) toxins to evolve resistance 
to. Importantly for the purposes of this issue, complete toxin resistance is not a necessity for feeding on toxic prey; for instance, feeding in specialist marsupial herbivores, which show some resistance via detoxification mechanisms, is still constrained due to incomplete resistance to one or more toxins in the diet (Lawler et al., 2000; Moore and Foley, 2005).

A mitigating factor in such evolutionary 'decisions' is that even if multiple different toxins are used by an organism, these may be functionally similar in that they may bind to the same (or very similar) physiological targets. This may simplify resistance substantially by creating a situation where the different toxins are all treated as a single one for the purposes of toxin resistance. This is seen in the case of diamondback moth larvae that have evolved resistance to four different Bacillus thuringiensis toxins via mutations in a single gene, presumed to be mediated by the target of all four toxins being similarly controlled by the product of this one gene (Tabashnik et al., 1997), and in the case of grasshopper mice resistance to bark scorpion venom for which a mutation in an off-target receptor seems to suffice to counteract the effect of a complex mixture of nociceptive toxins (Rowe et al., 2013).

Assuming an organism is faced with a mixture of toxins with a range of different physiological targets, as for instance is typical of venoms (Fry et al., 2009; Casewell et al., 2013), what would evolution would select for? We may surmise that if there are no costs to resistance then evolution should favour resistance to all toxins to eliminate deleterious effects, however, even in this ideal situation theoretical models predict that resistance to many toxins should be very slow (Speed et al., 2015) and hence inefficient. Furthermore, costs of toxin resistance are probably ubiquitous or nearly so and hence there should be a trade-off between the advantages of resistance and the various types of cost it may bring (e.g. Brodie and Brodie, 1999b; Ujvari et al., 2015; Tarvin et al., 2017). We would also expect that the particular trade-offs are likely to differ for each toxin resistance mechanism and hence that costs may be additive or perhaps even multiplicative in some circumstances, which would quickly lead to resistance against many toxins to be disfavoured by selection. In keeping with this assumption, theoretical work predicts that as more toxins are added to the prey's arsenal (which is beneficial to the prey even when toxins are costly to produce) the fitness of the predator drastically decreases as a result of the increasing costs of resistance (Speed et al., 2015). Consequently, the optimal strategy for the toxin producer should be to use many different toxins, whereas the optimal strategy for the toxin receiver should be to evolve resistance in a highly selective manner.

Taking venoms as an example, as these are typically highly complex mixtures, it is notable that despite the diversity of components there are typically relatively few which are presumed to be responsible for the major lethal effects, though others contribute to overall toxicity (e.g. Cordeiro et al., 2015; Ainsworth et al., 2017; Kalita et al., 2017; Tan et al., 2017). Coupled with the high diversity of toxins in venoms, several examples of resistance against venomous animals appear to focus on few toxin types of major effect and hence the predictions made in the previous paragraph are empirically supported. For instance, the resistance to viper venoms in several mammal species is predominantly based on inhibitors of snake venom metalloproteinases, which are often major toxins in the pathology of envenomations from these snakes (Pérez and Sánchez., 1999; Perales 
et al., 2005). Similarly, mammals which show resistance to elapid snakes often focus on the physiological targets of $\alpha$-neurotoxins (i.e. nicotinic acetylcholine receptors) which are often the major lethal components of the venom from these snakes (Drabeck et al., 2015). Notably, honey badgers show broad resistance to both viper and elapid snakes and have evolved both venom metalloproteinase inhibitors and altered nicotinic acetylcholine receptors (Drabeck et al., 2015), but have also been reported to suffer some minor (non-lethal) symptoms of envenomation, suggesting that resistance has indeed focussed on a few major toxic components rather than whole venoms.

\subsection{Coevolution and the inequality of predator and prey}

Although coevolution is a fundamental component of toxin resistance, the relative strengths of selection of the two parties involved will vary. Specifically, in these interactions predators and prey are subject to fundamental ecological inequalities that can alter the strength of selection and hence could determine the probability that toxin resistance evolves and (perhaps) how effective it is once it does evolve. Notably however, the direction of this inequality is not fixed per se, but will be dependent on the relative degree of trophic specialism of the predator.

If we consider a predator which could feed on toxic prey, resistance should be favoured when the predator is a diet specialist since the costs of toxin resistance can be compensated by the trait providing access to the majority of the diet. There may also be further coevolution between diet breadth and resistance since many potential predators will be unable to feed on toxic prey and hence reduced competition should provide additional selection pressure. This situation could even lead to accelerated selection pressure where an initial partial resistance to prey toxins may lead to new and stronger selection to improve this resistance. This could be investigated in a comparative study considering a quantitative measure of toxin resistance and testing for a positive relationship between rates of evolution of toxin resistance with the actual value (i.e. magnitude) of that trait. In contrast, for highly generalist predators, selection for toxin resistance is likely to be far weaker since the costs of resistance will often outweigh the benefit of adding one more diet item to an already broad range of options. In support of this conceptual model, diet specialism in caterpillars is often associated with a higher degree of resistance to host plant toxins (and particularly in those species which sequester toxins) despite lower levels of toxin resistance being found in some generalist species (Dyer, 1995; Nishida, 2002; Ali and Agrawal, 2012). Similarly, even amongst vertebrates, we note that horned lizards (Phrynosoma) have also evolved resistance to the venom of their ant prey (Schmidt et al, 1989) and again in this case we find that Phrynosoma are specialists on ants. We note that specialist predators could simply switch diet rather than evolve toxin resistance, but in many cases (dietary) specialisation seems to be difficult to lose in favour of generalism (Futuyma and Moreno, 1988; Darst et al., 2005), so in coevolving predator-prey systems it may not be 'evolutionary easy' for a predator to stop specialising on a prey animal which has evolved a toxic defence.

In the context of toxin resistance in prey to venomous predators, we should expect selection for resistance to be equally strong when there is one predominant predator or predator type (that uses similar venom to attack prey). This is for similar reasons as discussed above for resistant predators, but in the case of resistant prey the costs of 
failing to be resistant when needed are higher (death vs reduced diet breadth, related to Dawkins' and Krebs' 'life-dinner' principle [Dawkins and Krebs, 1979]) and so the threshold for the evolution of resistance in prey should be lower than that for predators. In other words, if we expect predators to be selected for toxin resistance when the proportion of toxic potential prey in the diet exceeds 0.7 , we might only expect the proportion of predators that are toxic to be 0.3 before toxin resistance in prey evolves (values here are arbitrary and would certainly be dependent on multiple other factors, including for instance the availability of alternative prey). Nevertheless, we expect that dietary specialism (in predators) is likely to be more common in nature than the situation where the suite of predators faced by a given prey species is dominated by a single predator species. Hence, we expect resistance against a chemically-armed predator (defensive toxin resistance) to be rarer than resistance against a chemically-armed prey (predatory toxin resistance). We note that this appears to be the case based on our current understanding (e.g. McCabe and Mackessy, 2017), however more information is needed on the diversity of toxin resistance in nature to properly test this hypothesis.

Finally, we highlight that the above discussion has focussed on a dichotomy between resistant predators and resistant prey. However, predicting the relative frequency and strength of toxin resistance is likely to be more difficult in many cases due to multiple factors that could cause deviations from the evolutionary framework we outline above. For instance, if many prey species use similar toxins due to convergence or radiations of toxic lineages, then resistance in predators will be more likely to evolve than in the simple one-to-one examples discussed above. Presenting even more difficulty for predicting the evolution of degrees of resistance is the various tritrophic interactions already mentioned throughout this review. For instance, opossums play both the role of predator and prey in their interactions with venomous pitvipers (Voss, 2013); therefore understanding the relative contributions of the resistant predator and resistant prey scenarios we discuss above is particularly problematic. Consequently, simple systems involving a single toxin user and a single resistant animal are likely to prove the most tractable approaches for testing these hypotheses.

\section{Conclusion}

Toxin resistance is an important part of the natural history of animals; a wide range of species bear toxic weaponry which has necessarily imposed selection pressure on the recipients of these offensive and defensive traits. Nevertheless, despite extensive research literature relating to the other side of the coevolutionary interaction, toxin resistance has been comparatively understudied and almost certainly underreported. This has left several interesting questions poorly understood. Within this review, we have attempted not only to summarise the current state of knowledge of toxin resistance, but also to point out areas where our knowledge is lacking such that future work relating to these questions will prove fruitful. We have also attempted to discuss generalities and patterns in the evolution of toxin resistance as this may provide a more cohesive conceptual framework which future researchers can use to help generate new questions for study. Overall, the field of toxin resistance has progressed to a point where much groundwork has been laid but many important questions remain; this is therefore likely 
to be a fertile platform for investigators who can bring new ideas and new approaches to this stimulating topic.

\section{Acknowledgements}

RCRV venom research was funded by a Marie Sklowdowska-Curie/Pres-SUD grant (COFUND No. 246556). RCRV and NRC would like to thank M. Daly and L. Gibbs for organizing the NESCent catalysis meeting on "Integrating Organismal and Applied Perspectives on Animal Venom Diversity" that served as starting point for some of the ideas expressed here. Authors would like to thank three anonymous reviewers, whose comments to a previous version of this manuscript helped us to improve our exposition.

\section{References}

Ainsworth, S., Petras, D., Engmark, M., Süssmuth, R.D., Whiteley, G., Albulescu, L.O., Kazandjian, T.D., Wagstaff, S.C., Rowley, P., Wüster, W., Dorrestein, P.C., Arias, A.S., Gutiérrez, J.M., Harrison, R.A., Casewell, N.R. and Calvete, J.J. 2017. The medical threat of mamba envenoming in sub-Saharan Africa revealed by genuswide analysis of venom composition, toxicity and antivenomics profiling of available antivenoms. Journal of Proteomics. In press. doi: 10.1016/j.jprot.2017.08.016.

Ali, J.G. and Agrawal, A.A. 2012. Specialist versus generalist insect herbivores and plant defense. Trends in Plant Science 17:293 - 302

Arbuckle, K. 2017. Evolutionary context of venom in animals; in Malhotra, A. and Gopalakrishnakone, P. (eds) Evolution of Venomous Animals and Their Toxins (Springer Handbook of Toxinology series). Springer, Netherlands

Arendt, J. and Reznick, D. 2008. Convergence and parallelism reconsidered: what have we learned about the genetics of adaptation? Trends in Ecology and Evolution 23:26 - 32

Bane, V., Lehane, M., Dikshit, M., O'Riordan, A. and Furey, A. 2014. Tetrodotoxin: chemistry, toxicity, source, distribution and detection. Toxins (Basel) 6:693 - 755

Barchan, D., Kachalsky, S., Neumann, D., Vogel, Z., Ovadia, M., Kochva, E., and Fuchs, S. 1992. How the mongoose can fight the snake: the binding site of the mongoose acetylcholine receptor. Proceedings of the National Academy of Sciences, 89(16):7717 - 7721.

Biardi, J.E., Ho, C.Y., Marcinczyk, J., and Nambiar, K.P. 2011. Isolation and identification of a snake venom metalloproteinase inhibitor from California ground squirrel (Spermophilus beecheyi) blood sera. Toxicon 58(6-7): 486 - 93.

Biardi, J.E., Chien, D.C. and Coss, R.G. 2006. California ground squirrel (Spermophilus beecheyi) defenses against rattlesnake venom digestive and hemostatic toxins. Journal of Chemical Ecology 32(1): 137 - 54.

Biardi, J.E. and Coss, R.G. 2011. Rock squirrel (Spermophilus variegatus) blood sera affects proteolytic and hemolytic activities of rattlesnake venoms. Toxicon 57(2): $323-31$.

Biardi, J.E., Coss, R.G. and Smith, D.G. 2000. California ground squirrel (Spermophilus beecheyi) blood sera inhibits crotalid venom proteolytic activity. Toxicon 38(5): 713 -21 . 
Bricelj, V.M., Connell, L., Konoki, K., Macquarrie, S.P., Scheuer, T., Catterll, W.A. and Trainer, V.L. 2005. Sodium channel mutation leading to saxitoxin resistance in clams increases risk of PSP. Nature 434:763 - 767

Brodie, E.D. III. 2009. Toxins and venoms. Current Biology 19:R931 - R935

Brodie E.D. III and Brodie E.D. Jr. 1991. Evolutionary response of predators to dangerous prey: reduction of toxicity of newts and resistance of garter snakes in island populations. Evolution 45:221 - 224

Brodie E.D. III and Brodie E.D. Jr. 1999a. Predator-prey arms races. BioScience 49:557 $-568$

Brodie E.D. III and Brodie E.D. Jr. 1999b. Costs of exploiting poisonous prey: evolutionary trade-offs in a predator-prey arms race. Evolution 53:626 - 631

Brodie, E.D. III and Ridenhour, B.J. 2003. Reciprocal selection at the phenotypic interface of coevolution. Integrative and Comparative Biology 43:408 - 418

Brodie, E.D. III and Brodie, E.D. Jr. 2015. Predictably convergent evolution of sodium channels in the arms race between predators and prey. Brain, Behavior and Evolution 86:48 - 57

Brodie, E.D. III, Feldman, C.R., Hanifin, C.T., Motychak, J.E., Mulcahy, D.G., Williams, B.L. and Brodie, E.D. Jr. 2005. Parallel arms races between garter snakes and newts involving tetrodotoxin as the phenotypic interface of coevolution. Journal of Chemical Ecology 31:343 - 356

Burchfield, P.M. 1977. Breeding the king cobra Ophiophagus hannah at Brownsville Zoo. International Zoo Yearbook 17:136 - 140

Burden, S.J., Hartzell, H.C. and Yoshikami, D. 1975. Acetylcholine receptors at neuromuscular synapses: phylogenetic differences detected by snake $\alpha$ neurotoxins. Proceedings of the National Academy of Sciences 72:3245 - 3249

Calvete, J.J. 2017. Venomics: integrative venom proteomics and beyond. Biochem $J$ 474:611 - 634

Carval, D. and Ferriere, R. 2010. A unified model for the coevolution of resistance, tolerance, and virulence. Evolution 64:2988 - 3009.

Casewell, N.R., 2012. On the ancestral recruitment of metalloproteinases into the venom of snakes. Toxicon 60(4):449 - 454.

Casewell, N.R., Wüster, W., Vonk, F.J., Harrison, R.A., and Fry, B.G. 2013. Complex cocktails: the evolutionary novelty of venoms. Trends in Ecology and Evolution, 28(4):219- 29.

Christin, P.-A., Weinreich, D.M. and Besnard, G. 2010. Causes and evolutionary significance of genetic convergence. Trends in Genetics 26:400 - 405

Clayton, D.H., Bush, S.E. and Johnson, K.P. 2015. Coevolution of Life on Hosts: Integrating Ecology and History. University of Chicago Press, Chicago

Cooper, A.M., Nelsen, D.R. and Hayes, W.K. 2017. The strategic use of venom by spiders; in Malhotra, A. and Gopalakrishnakone, P. (eds) Evolution of Venomous Animals and Their Toxins (Springer Handbook of Toxinology series). Springer, Netherlands

Cordeiro, F.A., Amorim, F.G., Anjolette, F.A.P. and Arantes, E.C. 2015. Arachnids of medical importance in Brazil: main active compounds present in scorpion and spider venoms and tick saliva. Journal of Venomous Animals and Toxins Including Tropical Diseases 21:24

Coss, R.G. and Owings, D.H., 1985. Restraints on ground squirrel antipredator behavior: adjustments over multiple time scales; in Johnson, T.D. and Pietrewicz, A.T. (eds) 
Issues in the Ecological Study of Learning. Erlbaum Assoc, New Jersey, USA.

Daly, J.W., Myers, C.W., Warnick, J.E., and Albuquerque, E.X. 1980. Levels of batrachotoxin and lack of sensitivity to its action in poison-dart frogs (Phyllobates). Science 208:1383 - 1385

Darst, C.R., Menéndez-Guerrero, P.A., Coloma, L.A. and Cannatella, D.C. 2005. Evolution of dietary specialization and chemical defense in poison frogs (Dendrobatidae): a comparative analysis. American Naturalist 165:56 - 69

Dawkins, R. and Krebs, J.R. 1979. Arms races between and within species. Proceedings of the Royal Society B 205:485 - 511

Davies, J. and Davies, D. 2010. Origins and evolution of antibiotic resistance. Microbiology and Molecular Biology Reviews 74:417 - 433

Dellisanti, C.D., Yao, Y., Stroud, J.C., Wang, Z.Z., and Chen, L. 2007a. Structural determinants for $\alpha$-neurotoxin sensitivity in muscle nAChR and their implications for the gating mechanism. Channels 1(4):234 - 237.

Dellisanti, C.D., Yao, Y., Stroud, J.C., Wang, Z.Z., and Chen, L. 2007b. Crystal structure of the extracellular domain of $n A C h R$ a 1 bound to a-bungarotoxin at $1.94 \AA$ resolution. Nature Neuroscience, 10(8):953 - 962.

Deng, M., Hu, Z., Cai, T., Liu, K., Wu, W., Luo, K., Wu, W., Luo, X., Jiang, L., Wang, M., Yang, J., Xiao, Y. and Liang, S. 2016. Characterization of ion channels on subesophageal ganglion neurons from Chinese tarantula Ornithoctonus huwena: exploring the myth of the spider insensitive to its venom. Toxicon 120:61 - 68

Dimitropoulos, N., Papakyriakou, A., Dalkas, G.A., Chasapis, C.T., Poulas, K., and Spyroulias, G.A. 2011. A computational investigation on the role of glycosylation in the binding of alpha1 nicotinic acetylcholine receptor with two alpha-neurotoxins. Proteins: Structure, Function, and Bioinformatics 79(1):142 - 152.

Dobler, S., Dalla, S., Wagschal, V., and Agrawal, A.A. 2012. Community-wide convergent evolution in insect adaptation to toxic cardenolides by substitutions in the Na,K-ATPase. Proceedings of the National Academy of Sciences USA 109(32):13040 - 5.

Drabeck, D.H., Dean, A.M. and Jansa, S.A. 2015. Why the honey badger don't care: Convergent evolution of venom-targeted nicotinic acetylcholine receptors in mammals that survive venomous snake bites. Toxicon 99:68 - 72 .

Duffey, S.S. and Towers, G.H.N. 1978. On the biochemical basis of HCN production in the millipede Harpaphe haydeniana (Xystodesmidae: Polydesmida). Canadian Journal of Zoology 56:7 - 16

Dumbacher, J.P., Wako, A., Derrickson, S.R., Samuelson, A., Spande, T.F. and Daly, J.W. 2004. Melyrid beetles (Choresine): a putative source for the batrachotoxin alkaloids found in poison-dart frogs and toxic passerine birds. Proceedings of the National Academy of Sciences 101:15857 - 15860

Dutertre, S., Jin, A.H., Vetter, I., Hamilton, B., Sunagar, K., Lavergne, V., Dutertre, V., Fry, B.G., Antunes, A., Venter, D.J., Alewood, P.F. and Lewis, R.J. 2014. Evolution of separate predation- and defence-evoked venoms in carnivorous cone snails. Nature Communications 5:3521

Dyer, L.A. 1995. Tasty generalists and nasty specialists? Antipredator mechanisms in tropical lepidopteran larvae. Ecology 76:1483 - 1496

Edstrom, A. 1992. Venomous and Poisonous Animals. Krieger Publishing Company, Florida

Faure, G., 2000. Natural inhibitors of toxic phospholipases A2. Biochimie 82(9):833 - 
840.

Feldman, C.R., Brodie E.D. Jr., Brodie E.D. III, and Pfrender, M.E. 2010. Genetic architecture of a feeding adaptation: garter snake (Thamnophis) resistance to tetrodotoxin bearing prey. Proceedings of the Royal Society B 277:3317 - 3325

Feldman, C.R., Brodie E.D. Jr., Brodie E.D. III, and Pfrender, M.E. 2012. Constraint shapes convergence in tetrodotoxin-resistant sodium channels of snakes. Proceedings of the National Academy of Science USA 109:4556 - 4561

Feldman, C.R., Durso, A.M., Hanifin, C.T., Pfrender, M.E., Ducey, P.K., Stokes, A.N., Barnett, K.E., Brodie E.D. III and Brodie E.D. Jr. 2016. Is there more than one way to skin a newt? Convergent toxin resistance in snakes is not due to a common genetic mechanism. Heredity 116:84 - 91

Fitch, H.S., 1948. Ecology of the California ground squirrel on grazing lands. Am. Midl. Nat., 39:513.

Ffrench-Constant, R.H. 2013. The molecular genetics of insecticide resistance. Genetics 194:807- 815

Fry, B.G., Roelants, K., Champagne, D.E., Scheib, H., Tyndall, J.D.A., King, G.F., Nevalainen, T.J., Norman, J.A., Lewis, R.J., Norton, R.S., Renjifo, C., and Rodríguez de la Vega, R.C. 2009. The toxicogenomic multiverse: convergent recruitment of proteins into animal venoms. Annual Review of Genomics and Human Genetics 10:483 - 511

Fukuda, K., Doggett, T., Laurenzi, I.J., Liddington, R.C. and Diacovo, T.G., 2005. The snake venom protein botrocetin acts as a biological brace to promote dysfunctional platelet aggregation. Nature Structural \& Molecular Biology, 12(2):152 - 159.

Futuyma, D.J. and Moreno, G. 1988. The evolution of ecological specialization. Annual Review of Ecology and Systematics 19:207 - 233

Garcia, V.E. and Perez, J.C. 1984. The purification and characterization of an antihemorrhagic factor in woodrat (Neotoma micropus) serum. Toxicon 22(1):129 38.

Geffeney, S.L., Fujimoto, E., Brodie, E.D. III, Brodie, E.D. Jr. and Ruben, P.C. 2005. Evolutionary diversification of TTX-resistant sodium channel in a predator-prey interaction. Nature 434:759 - 763

Gleibs, S. and Mebs, D. 1999. Distribution and sequestration of palytoxin in coral reef animals. Toxicon 37:1521 - 1527

Gould, S.J. and Vrba, E.S. 1982. Exaptation - a missing term in the science of form. Paleobiology 8:4 - 15

Guenneugues, M. and Menez, A. 1997. Structures et fonctions de toxines animales. Comptes Rendus des Séances de la Société de Biologie et de ses Filiales 191:329 - 344

Hanifin, C.T. and Gilly, W.F. 2015. Evolutionary history of a complex adaptation: tetrodotoxin resistance in salamanders. Evolution 69:232 - 244

Harris, R.J. and Arbuckle, K. 2016. Tempo and mode of the evolution of venom and poison in tetrapods. Toxins 8:193

Hayes, W.K. 1995. Venom metering by juvenile prairie rattlesnakes, Crotalus v. viridis: effects of prey size and experience. Animal Behaviour 50:33 - 40

Heckel, D.G., Gahan, L.J., Baxter, S.W., Zhao, J.-Z., Shelton, A.M., Gould, F. and Tabashnik, B.E. 2007. The diversity of $\mathrm{Bt}$ resistance genes in species of Lepidoptera. Journal of Invertebrate Pathology 95:192 - 197

Herbert, S.S. and Hayes, W.K. 2009. Denim clothing reduces venom expenditure by 
rattlesnakes striking defensively at model human limbs. Annals of Emergency Medicine 54:830 - 836

Holding, M.L., Biardi, J.E. and Gibbs, H.L. 2016a. Coevolution of venom function and venom resistance in a rattlesnake predator and its squirrel prey. Proceedings Biological Sciences 283(1829):20152841

Holding, M.L., Drabeck, D.H., Jansa, S.A. and Gibbs, H.L. 2016b. Venom resistance as a model for understanding the molecular basis of complex coevolutionary adaptations. Integrative and Comparative Biology 56:1032 - 1043

Hutchinson, D.A., Mori, A., Savitzky, A.H., Burghardt, G.M., Wu, X., Meinwald, J. and Schroeder, F.C. 2007. Dietary sequestration of defensive steroids in nuchal glands of the Asian snake Rhabdophis tigrinus. Proceedings of the National Academy of Science of the USA 104:2265 - 2270

Hutchinson, D.A., Savitzky, A.H., Mori, A., Meinwald, J. and Schroeder, F.C. 2008. Maternal provisioning of sequestered defensive steroids by the Asian snake Rhabdophis tigrinus. Chemoecology 18:181 - 190

Hutchinson, D.A., Savitzky, A.H., Mori, A., Burghardt, G.M., Meinwald, J. and Schroeder, F.C. 2012. Chemical investigations of defensive steroid sequestration by the Asian snake Rhabdophis tigrinus. Chemoecology 22:199 - 206

Huxley-Jones, J., Clarke, T.K., Beck, C., Toubaris, G., Robertson, D.L., Boot-Handford, R.P. 2007. The evolution of the vertebrate metzincins; insights from Ciona intestinalis and Danio rerio. BMC Evolutionary Biology 7(1):63

Inceoglu, B., Lango, J., Jing, J., Chen, L., Doymaz, F., Pessah, I.N. and Hammock, B.D. 2003. One scorpion, two venoms: prevenom of Parabuthus transvaalicus acts as an alternative type of venom with distinct mechanisms of action. Proceedings of the National Academy of Sciences USA 100:922 - 927

Israel, M.R., Tay, B., Deuis, J.R. and Vetter, I. 2017. Sodium channels and venom peptide pharmacology. Advances in Pharmacology 79:67 - 116

Jansa, S.A. and Voss, R.S., 2011. Adaptive evolution of the venom-targeted vWF protein in opossums that eat pitvipers. PLoS ONE 6(6):e20997.

Jost, M.C., Hillis, D.M., Lu, Y., Kyle, J.W., Fozzard, H.A. and Zakon, H.H. 2008. Toxinresistant sodium channels: parallel adaptive evolution across a complete gene family. Molecular Biology and Evolution 25:1016 - 1024

Jurgilas, P.B., Neves-Ferreira, A.G., Domont, G.B., and Perales, J. 2003. PO41, a snake venom metalloproteinase inhibitor isolated from Philander opossum serum. Toxicon 42(6):621 - 628.

Kalita, B., Patra, A. and Mukherjee, A.K. 2017. Unraveling the proteome composition and immuno-profiling of western India Russell's viper venom for in-depth understanding of its pharmacological properties, clinical manifestations, and effective antivenom treatment. Journal of Proteome Research 16:583 - 598

Kojima, Y. and Mori, A. 2015. Active foraging for toxic prey during gestation in a snake with maternal provisioning of sequestered chemical defences. Proceedings of the Royal Society B 282:20142137

Lawler, I.R., Foley, W.J. and Eschler, B.M. 2000. Foliar concentration of a single toxin creates habitat patchiness for a marsupial folivore. Ecology 81:1327 - 1338

Lizano, S., Lomonte, B., Fox, J.W., and Gutiérrez, J.M. 1997. Biochemical characterization and pharmacological properties of a phospholipase A2 myotoxin inhibitor from the plasma of the snake Bothrops asper. The Biochemical Journal, 326(Pt 3):853 - 859. 
Lizano, S., Angulo, Y., Lomonte, B., Fox, J.W., Lambeau, G., Lazdunski, M., and Gutiérrez, J.M. 2000. Two phospholipase A2 inhibitors from the plasma of Cerrophidion (Bothrops) godmani which selectively inhibit two different group-II phospholipase A2 myotoxins from its own venom: isolation, molecular cloning and biological properties. The Biochemical Journal, 346(Pt 3):631 -639.

Losos, J.B. 2011. Convergence, adaptation, and constraint. Evolution 65:1827 - 1840

Mackessy, S.P. and Baxter, L.M. 2006. Bioweapons synthesis and storage: the venom gland of front-fanged snakes. Zoologische Anzeiger 245:147 - 159

Malcolm, S.B. and Brower, L.P. 1989. Evolutionary and ecological implications of cardenolide sequestration in the monarch butterfly. Experientia 45:284 - 295

Martínez, J.L. 2008. Antibiotics and antibiotic resistance genes in natural environments. Science 321:365 - 367

McCabe, T.M. and Mackessy S.P. 2017. Evolution of resistance to toxins in prey; in Malhotra, A. and Gopalakrishnakone, P. (eds) Evolution of venomous animals and their toxins (Springer Handbook of Toxinology series). Springer, Netherlands.

McCue, M.D. 2006. Cost of producing venom in three North American pitviper species. Copeia 2006:818 - 825

McGlothlin, J.W., Chuckalovcak, J.P., Janes, D.E., Edwards, S.V., Feldman, C.R., Brodie, E.D. Jr., Pfrender, M.E., and Brodie, E.D. III. 2014. Parallel evolution of tetrodotoxin resistance in three voltage-gated sodium channel genes in the garter snake Thamnophis sirtalis. Molecular Biology and Evolution, 31(11):2836-46.

McGlothlin, J.W., Kobiela, M.E., Feldman, C.R., Castoe, T.A., Geffeney, S.L., Hanifin, C.T., Toledo, G., Vonk, F.J., Richardson, M.K., Brodie E.D. Jr., Pfrender, M.E. and Brodie E.D. III. 2016. Historical contingency in a multigene family facilitates adaptive evolution of toxin resistance. Current Biology 26:1616 - 1621

Mebs, D. 2002. Venomous and Poisonous Animals: A Handbook for Biologists, Toxicologists and Toxinologists, Physicians and Pharmacists. CRC Press, Boca Raton, U.S.A.

Mohammadi, S., Gompert, Z., Gonzalez, J., Takeuchi, H., Mori, A. and Savitzky, A.H. 2016. Toxin-resistant isoforms of $\mathrm{Na}+\mathrm{K}+-\mathrm{ATPase}$ in snakes do not closely track dietary specialization. Proceedings of the Royal Society B 283:20162111

Moore, B.D. and Foley, W.J. 2005. Tree use by koalas in a chemically complex landscape. Nature 435:488 - 490

Moore, D.J., Halliday, D.C., Rowell, D.M., Robinson, A.J., and Keogh, J.S. 2009. Positive Darwinian selection results in resistance to cardioactive toxins in true toads (Anura: Bufonidae). Biology Letters, 5(4):513 - 516.

Morgenstern, D. and King, G.F. 2013. The venom optimization hypothesis revisited. Toxicon 63:120 - 128

Nelsen, D.R., Nisani, Z., Cooper, A.M., Fox, G.A., Gren, E.C., Corbit, A.G. and Hayes, W.K. 2014. Poisons, toxungens, and venoms: redefining and classifying toxic biological secretions and the organisms that employ them. Biological Reviews 89:450 - 465

Neumann, D., Barchan, D., Fridkin, M., and Fuchs, S. 1986. Analysis of ligand binding to the synthetic dodecapeptide 185-196 of the acetylcholine receptor alpha subunit. Proceedings of the National Academy of Sciences USA 83(23):9250 - 9253.

Neves-Ferreira, A.G., Cardinale, N., Rocha, S.L., Perales, J., and Domont, G.B. 2000. Isolation and characterization of DM40 and DM43, two snake venom metalloproteinase inhibitors from Didelphis marsupialis serum. Biochimica et 
Biophysica Acta, 1474(3):309 - 320.

Neves-Ferreira, A.G., Perales, J., Fox, J.W., Shannon, J.D., Makino, D.L., Garatt, R.C., and Domont, G.B. 2002. Structural and functional analyses of DM43, a snake venom metalloproteinase inhibitor from Didelphis marsupialis serum. Journal of Biological Chemistry, 277(15):13129 - 37.

Nisani, Z. and Hayes, W.K. 2011. Defensive stinging by Parabuthus transvaalicus scorpions: risk assessment and venom metering. Animal Behaviour 81:627 - 633

Nisani, Z., Dunbar, S.G. and Hayes, W.K. 2007. Cost of venom regeneration in Parabuthus transvaalicus (Arachnida: Buthidae). Comparative Biochemistry and Physiology Part A: Molecular and Integrative Physiology 147:509 - 513

Nishida, R. 2002. Sequestration of defensive substances from plants by Lepidoptera. Annual Review of Entomology 47:57 - 92

Ohkura, N., Okuhara, H., Inoue, S., Ikeda, K., and Hayashi, K. 1997. Purification and characterization of three distinct types of phospholipase A2 inhibitors from the blood plasma of the Chinese mamushi, Agkistrodon blomhoffii siniticus. Biochemical Journal, 325(2):527 - 531.

Omori-Satoh, T., Nagaoka, Y., Yamakawa, Y., and Mebs, D. 1994. Inhibition of hemorrhagic activities of various snake venoms by purified antihemorrhagic factor obtained from Japanese Habu snake. Toxicon 32(3):365 - 368.

Omori-Satoh, T., Sadahiro, S., Ohsaka, A., and Murata, R. 1972. Purification and characterization of an antihemorrhagic factor in the serum of Trimeresurus flavoviridis, a crotalid. Biochimica et Biophysica Acta (BBA) - Protein Structure, 285(2):414 - 426.

Opitz, S.E.W. and Müller, C. 2009. Plant chemistry and insect sequestration. Chemoecology 19:117 - 154

Ovadia, M. \& Kochva, E., 1977. Neutralization of Viperidae and Elapidae snake venoms by sera of different animals. Toxicon, 15(6):541 - 547 .

Perales Moussatche, H., Marangoni, S., Oliveira, B., Domont, G.B., J., 1994. Isolation and partial characterization of an antibothropic complex from serum of South American Didelphidae. Toxicon, 32, pp.1237-1249.

Perales, J., Neves-Ferreira, A.G., Valente, R.H., and Domont, G.B. 2005. Natural inhibitors of snake venom hemorrhagic metalloproteinases. Toxicon 45(8):1013 20.

Perez, J.C., Haws, W.C., Garcia, V.E., and Jennings, B.M. III. 1978a. Resistance of warm-blooded animals to snake venoms. Toxicon 16(4):375 - 383.

Perez, J.C., Haws, W.C., and Hatch, C.H. 1978b. Resistance of woodrats (Neotoma micropus) to Crotalus atrox venom. Toxicon 16(2):198 - 200.

Perez, J.C., Pichyangkul, S., and Garcia, V.E., 1979. The resistance of three species of warm-blooded animals to western diamondback rattlesnake (Crotalus atrox) venom. Toxicon 17(6):601 - 607.

Pérez, J.C., and Sánchez, E.E. 1999. Natural protease inhibitors to hemorrhagins in snake venoms and their potential use in medicine. Toxicon, 37(5):703- 728.

Petschenka, G. and Agrawal, A.A. 2015. Milkweed butterfly resistance to plant toxins is linked to sequestration, not coping with a toxic diet. Proceedings of the Royal Society B 282:20151865

Philpot, B. Jr., Ezekiel, E., Laseter, Y., Yaeger, R.G., Stjernholm, R.L. 1978. Neutralization of crotalid venoms by fractions from snake sera. Toxicon 16(6):603609. 
Pichyangkul, S., and Perez, J.C., 1981. Purification and characterization of a naturally occurring antihemorrhagic factor in the serum of the hispid cotton rat (Sigmodon hispidus). Toxicon 19(2):205 - 215.

Pintor, A.F.V., Krockenberger, A.K. and Seymour, J.E. 2010. Costs of venom production in the common death adder (Acanthophis antarcticus). Toxicon 56:1035 - 1042

Pizzatto, L. and Shine, R. 2008. The behavioral ecology of cannibalism in cane toads (Bufo marinus). Behavioral Ecology and Sociobiology 63:123 - 133

Polis, G.A. and Myers, C.A. 1985. A survey of intraspecific predation among reptiles and amphibians. Journal of Herpetology 19:99 - 107

Pomento, A.M., Perry, B.W., Denton, R.D., Gibbs, H.L., and Holding, M.L. 2016. No safety in the trees: Local and species-level adaptation of an arboreal squirrel to the venom of sympatric rattlesnakes. Toxicon 118:149 - 155.

Poran, N.S., and Coss, R.G. 1990. Development of antisnake defenses in California ground squirrels (Spermophilus beecheyi): I. Behavioral and immunological relationships. Behaviour, 112(3):222 - 244.

Poran, N.S., Coss, R.G., and Benjamini, E., 1987. Resistance of California ground squirrels (Spermophilus beecheyi) to the venom of the northern Pacific rattlesnake (Crotalus viridis oreganus): A study of adaptive variation. Toxicon 25(7):767 - 777.

Read, M.S., Smith, S.V., Lamb, M.A., and Brinkhous, K.M. 1989. Role of botrocetin in platelet agglutination: formation of an activated complex of botrocetin and von Willebrand factor. Blood 74(3):1031 - 1035.

Rocha, S.L., Lomonte, B., Neves-Ferreira, A.G., Trugilho, M.R., Junqueira-de-Azevedo, I.L., Ho, P.L., Domont, G.B., Gutierrez, J.M., and Perales, J. 2002. Functional analysis of DM64, an antimyotoxic protein with immunoglobulin-like structure from Didelphis marsupialis serum. European Journal of Biochemistry 269(24):6052 6062.

Rodríguez, C., Rollins-Smith, L., Ibáñez, R., Durant-Archibold, A.A. and Gutiérrez, M. 2017. Toxins and pharmacologically active compounds from species of the family Bufonidae (Amphibia, Anura). Journal of Ethnopharmacology 198:235 - 254

Rowe, A.H. and Rowe, M.P. 2006. Risk assessment by grasshopper mice (Onychomys spp.) feeding on neurotoxic prey (Centruroides spp.). Animal Behaviour 71(3):725 $-734$.

Rowe, A.H. and Rowe, M.P. 2008. Physiological resistance of grasshopper mice (Onychomys spp.) to Arizona bark scorpion (Centruroides exilicauda) venom. Toxicon 52(5):597 - 605.

Rowe, A.H. and Rowe, M.P. 2015. Predatory grasshopper mice. Current Biology 25:R1023 - R1026

Rowe, A.H., Xiao, Y., Scales, J., Linse, K.D., Rowe, M.P., Cummins, T.R. and Zakon, H.H. 2011. Isolation and characterization of CvIV4: a pain inducing a-scorpion toxin. PLOS ONE 6:e23520

Rowe, A.H., Xiao, Y., Rowe, M.P., Cummins, T.R., and Zakon, H.H. 2013. Voltage-gated sodium channel in grasshopper mice defends against bark scorpion toxin. Science 342(6157):441 - 446.

Sanders, W.E., Read, M.S., Reddick, R.L., Garris, J.B., and Brinkhous, K.M. 1988. Thrombotic thrombocytopenia with von Willebrand factor deficiency induced by botrocetin. An animal model. Laboratory Investigation 59(4):443 - 52.

Santos, J.C., Tarvin, R.D. and O'Connell, L.A. 2016. A review of chemical defense in poison frogs (Dendrobatidae): ecology, pharmacokinetics, and autoresistance; in 
Schulte, B.A., Goodwin, T.E. and Ferkin, M.H. (eds) Chemical Signals in Vertebrates 13. Springer, Switzerland.

Savitzky, A.H., Mori, A., Hutchinson, D.A., Saporito, R.A., Burghardt, G.M., Lillywhite, H.B. and Meinwald, J. 2012. Sequestered defensive toxins in tetrapod vertebrates: principles, patterns, and prospects for future studies. Chemoecology 22:141 - 158

Schmidt, P.J., Sherbrooke, W.C. and Schmidt, J.O. 1989. The detoxification of ant (Pogonomyrmex) venom by a blood factor in horned lizards (Phrynosoma). Copeia 1989:603-607

Schneider, D.S. and Ayres, J.S. 2008. Two ways to survive infection: what resistance and tolerance can teach us about treating infectious diseases. Nature Reviews Immunology 8:889 - 895

Schoner, W., 2002. Endogenous cardiac glycosides, a new class of steroid hormones. European Journal of Biochemistry, 269(10):2440 - 2448.

Schwartz, E.N.F., Schwartz, C.A. and Sebben, A. 1998. Occurrence of hemolytic activity in the skin secretion of the caecilian Siphonops paulensis. Natural Toxins 6:179182

Shao, J., Shen, H. and Havsteen, B. 1993. Purification, characterization and binding interactions of the Chinese-cobra (Naja naja atra) serum antitoxic protein CSAP. The Biochemical journal, 293(Pt 2):559 - 566.

Sheumack, D.D., Howden, M.E., Spence, I., and Quinn, R.J. 1978. Maculotoxin: a neurotoxin from the venom glands of the octopus Hapalochlaena maculosa identified as tetrodotoxin. Science 199(4325):188-189.

Smith, M.T., Ortega, J. and Beaupre, S.J. 2014. Metabolic cost of venom replenishment by prairie rattlesnakes (Crotalus viridis viridis). Toxicon 86:1 - 7

Soares, A.M., Rodrigues, V.M., Borges, M.H., Andriao-Escarso, S.H., Cunha, O.A., Homsi-Brandeburgo, M.I., and Giglio, J.R. 1997. Inhibition of proteases, myotoxins and phospholipases A2 from Bothrops venoms by the heteromeric protein complex of Didelphis albiventris opossum serum. IUBMB Life 43(5):1091 - 1099.

Song, Y., Endepols, S., Klemann, N., Richter, D., Matuschka, F.-R., Shih, C.-H., Nachman, N.W. and Kohn, M.H. 2011. Adaptive introgression of anticoagulant rodent poison resistance by hybridization in Old World mice. Current Biology $21: 1296-1301$

Soong, T.W. and Venkatesh, B. 2006. Adaptive evolution of tetrodotoxin resistance in animals. Trends in Genetics 22:621 - 626

Speed, M.P. and Arbuckle, K. 2017. Quantification provides a conceptual basis for convergent evolution. Biological Reviews 92:815 - 829

Speed, M.P., Fenton, A., Jones, M.G., Ruxton, G.D. and Brockhurst, M.A. 2015. Coevolution can explain defensive secondary metabolite diversity in plants. New Phytologist 208:1251 - 1263

Stahl, E.A., Dwyer, G., Mauricio, R., Kreitman, M. and Bergelson, J. 1999. Dynamics of disease resistance polymorphism at the Rpm 1 locus of Arabidopsis. Nature 400:667 $-671$

Stern, D.L. 2013. The genetic causes of convergent evolution. Nature Reviews Genetics $14: 751-764$

Straight, R., Glenn, J.L. and Snyder, C.C. 1976. Antivenom activity of rattlesnake blood plasma. Nature 261(5557):259 - 260.

Tabashnik, B.E., Liu, Y.-B., Finson, N., Masson, L. and Heckel, D.G. 1997. One gene in diamondback moth confers resistance to four Bacillus thuringiensis toxins. 
Proceedings of the National Academy of Sciences 94:1640 - 1644

Tabashnik, B.E., Gassmann, A.J., Crowder, D.W. and Carriére, Y. 2008. Insect resistance to $B t$ crops: evidence versus theory. Nature Biotechnology 26:199 - 202

Takacs, Z., Wilhelmsen, K.C. and Sorota, S. 2001. Snake alpha-neurotoxin binding site on the Egyptian cobra (Naja haje) nicotinic acetylcholine receptor is conserved. Molecular Biology and Evolution, 18(9):1800 - 1809.

Takacs, Z., Wilhelmsen, K.C. and Sorota, S. 2004. Cobra (Naja spp.) nicotinic acetylcholine receptor exhibits resistance to Erabu sea snake (Laticauda semifasciata) short-chain a-neurotoxin. Journal of Molecular Evolution 58(5):516 526.

Tan, N.H., Wong, K.Y. and Tan, C.H. 2017. Venomics of Naja sputatrix, the Javan spitting cobra: a short neurotoxin-driven venom needing improved antivenom neutralization. Journal of Proteomics 157:18 - 32

Tarvin, R.D., Santos, J.C., O'Connell, L.A., Zakon, H.H. and Cannatella, D.C. 2016. Convergent substitutions in a sodium channel suggest multiple origins of toxin resistance in poison frogs. Molecular Biology and Evolution 33:1068 - 1081

Tarvin, R.D., Borghese, C.M., Sachs, W., Santos, J.C., Lu, Y., O'Connell, L.A. Cannatella, D.C., Harris, R.A. and Zakon, H.H. 2017. Interacting amino acid replacements allow poison frogs to evolve epibatidine resistance. Science 357:1261 $-1266$

Thompson, J.N. 1999. Coevolution and escalation: are ongoing coevolutionary meanderings important? American Naturalist 173:S92 - S93

Thuesen, E. et al., 1988. Poison arrow worms: a tetrodotoxin venom in the marine phylum Chaetognatha. Journal of Experimental Marine Biology and Ecology, 116(3), pp.249-256.

Thwin, M.M. \& Gopalakrishnakone, P., 1998. Snake envenomation and protective natural endogenous proteins: a mini review of the recent developments (19911997). Toxicon 36(11):1471-82.

Tomihara, Y., Kawamura, Y., Yonaha, K., Nozaki, M., Yamakawa, M., and Yoshida, C. 1990. Neutralization of hemorrhagic snake venoms by sera of Trimeresurus flavoviridis (Habu), Herpestes edwardsii (mongoose) and Dinodon semicarinatus (Akamata). Toxicon 28(8):989 - 991.

Twigg, L.E., Martin, G.R. and Lowe, T.J. 2002. Evidence of pesticide resistance in medium-sized mammalian pests: a case study with 1080 poison and Australian rabbits. Journal of Applied Ecology 39:549 - 560

Tzartos, S.J. and Remoundos, M.S., 1990. Fine localization of the major alphabungarotoxin binding site to residues alpha 189-195 of the Torpedo acetylcholine receptor. Residues 189, 190, and 195 are indispensable for binding. The Journal of Biological Chemistry, 265(35):21462 - 7.

Ujvari, B., Casewell, N.R., Sunagar, K., Arbuckle, K., Wuster, W., Lo, N., O’Meally, D., Beckmann, C., King, G.F., Deplazes, E., and Madsen, T. 2015. Widespread convergence in toxin resistance by predictable molecular evolution. Proceedings of the National Academy of Sciences USA 112(38):11911 - 11916

van der Meijden, A., Coelho, P. and Rasko, M. 2015. Variability in venom volume, flow rate and duration in defensive stings of five scorpion species. Toxicon 100:60 - 66

Van Valen, L. 1973. A new evolutionary law. Evolutionary Theory 1:1 - 30

Venkatesh, B., Lu, S.Q., Dandona, N., See, S.L., Brenner, S. and Soong, T.W. 2005. Genetic basis of tetrodotoxin resistance in pufferfishes. Current Biology 15:2069 - 
2072

Vermeij, G.J. 1987. Evolution and Escalation: An Ecological History of Life. Princeton University Press. New Jersey, USA.

Voss, R.S. 2013. Opossums (Mammalia: Didelphidae) in the diets of Neotropical pitvipers (Serpentes: Crotalinae): evidence for alternative coevolutionary outcomes? Toxicon 66:1 - 6

Voss, R.S. and Jansa, S.A. 2012. Snake-venom resistance as a mammalian trophic adaptation: lessons from didelphid marsupials. Biological Reviews 87:822 - 837

Wang, S.Y. and Wang, G.K. 2017. Single rat muscle Na+ channel mutation confers batrachotoxin autoresistance found in poison-dart frog Phyllobates terribilis. Proceedings of the National Academy of Sciences USA 114:10491 - 10496

Wang, X., Havsteen, B. and Hansen, H. 1995. Evidence of the coevolution of a snake toxin and its endogenous antitoxin cloning, sequence and expression of a serum albumin cDNA of the Chinese cobra. Biological Chemistry 376(9):545 - 553.

White, D.G., Zhao, S., Simjee, S., Wagner, D.D. and McDermott, P.F. 2002. Antimicrobial resistance of foodborne pathogens. Microbes and Infection 4:405 - 412

de Wit, C.A. 1982. Resistance of the prairie vole (Microtus ochrogaster) and the woodrat (Neotoma floridana), in Kansas, to venom of the Osage copperhead (Agkistrodon contortrix phaeogaster). Toxicon 20:709 - 714

de Wit, C.A. and Weström, B.R., 1987. Venom resistance in the hedgehog, Erinaceus europaeus: purification and identification of macroglobulin inhibitors as plasma antihemorrhagic factors. Toxicon 25(3):315 - 323.

Wood, J.N. 2013. Results in analgesia - Darwin 1, pharma 0. New England Journal of Medicine 369:2558 - 2560

Wong, E.S.W. and Belov, K. 2012. Venom evolution through gene duplications. Gene 496: 1 - 7

Zhen, Y., Aardema, M.L., Medina, E.M., Schumer, M., and Andolfatto, P. 2012. Parallel molecular evolution in an herbivore community. Science 337(6102):1634 - 7.

\section{Figure legends}

Fig. 1. Phylogeny of major animal clades with red terminal branches highlighting those which have had toxin resistance reported from at least one species (note that this is not an ancestral state reconstruction). Taxa were chosen arbitrarily to illustrate the diversity of lineages in which toxin resistance has been documented, rather than a representative sample of animal clades (hence the taxonomic level of tips varies markedly to better highlight this diversity). The topology reflects our current understanding of these groups (reflected in several sources such as http://timetree.org/), and the few still-debated relationships (e.g. the placement of turtles) do not detract from the schematic of the taxonomic breadth of animals with demonstrated toxin resistance.

Fig. 2. Examples of toxin resistance mediated by toxin scavenging and off-target repurposing. A) An example of toxin scavenging. The protein DM43 from opossum (Didelphis marsupialis) serum inhibits the activity of snake venom metalloproteinases by 
binding to them in a 1:1 manner, resulting in a loss of activity and subsequent clearance (Perales Moussatche et al. 1994; Neves-Ferreira et al. 2000, 2002). The image shows a structural model of DM43 (https://swissmodel.expasy.org/repository/uniprot/P82957) with the proposed metalloproteinase binding site coloured in green. B) An example of off-target repurposing. Scorpion venom toxins interact with $\mathrm{Nav}$ channels to cause pain, but have no effect on $\mathrm{Na}_{\mathrm{v}} 1.8$. Resistant grasshopper mice (Onychomys torridus) have two amino acid changes in the SS2-S6 linker region of $\mathrm{Na}_{v} 1.8$ which promote the binding of scorpion toxins, resulting in the inhibition of $\mathrm{Na}^{+}$currents, and the induction of analgesia (Rowe et al. 2013). The image shows the amino acids responsible for promoting binding in this off-target $\mathrm{Na}_{v}$ channel, and hence venom resistance, compared to naïve venom-sensitive mice (Mus musculus).

Fig. 3. Examples of toxin resistance mediated by target site insensitivity. A) Convergent molecular changes to the nicotinic acetylcholine receptor (nAChR) confer resistance to snake venom $\alpha$-neurotoxins by reducing affinity via charge interference or resulting in glycosylation causing steric hindrance (Dellisanti et al. 2007a, 2007b; Takacs et al., 2001; Takacs et al., 2004; Drabeck et al. 2015). The image shows the different amino acids replacements detected in the nAChR of a variety of mammals and the cobra (autoresistance) that confer toxin resistance. B) Convergent molecular changes to the sodium-potassium pump ( $\mathrm{Na}^{+} / \mathrm{K}^{+}$-ATPase) confer resistance to bufonid toad cardiac glycosides by reducing affinity via charge interference (Ujvari et al. 2015). The image shows the different amino acid replacements detected in the $\mathrm{Na}^{+} / \mathrm{K}^{+}-\mathrm{ATP}$ ase of a variety of vertebrates, including bufonid toads (autoresistance), that confer toxin resistance. 